\title{
The Avon Longitudinal Study of Parents and Children (ALSPAC) - study design and collaborative opportunities
}

\author{
Jean Golding and the ALSPAC Study Team \\ Department of Community Based Medicine, 24 Tyndall Avenue, Bristol BS8 1TQ, UK \\ (Correspondence should be addressed to J Golding; Email: jean.golding@bristol.ac.uk)
}

\begin{abstract}
The Avon Longitudinal Study of Parents and Children (ALSPAC) is a population-based study designed to understand the ways in which the physical and social environment interact, over time, with the genotype to affect health, behaviour and development. This information about causal interactions in common diseases and disorders will provide the basis on which future preventive interventions can be tested, especially in regard to people with specific genotypes. Whilst ALSPAC builds on data and hypotheses generated by earlier general population cohorts, its design offers special advantages, the most important being: enrolment in early pregnancy; banking of DNA from the children and parents (permitting genetic transmission tests and transgenerational imprinting studies); diverse physical, psychological and environmental measures; one geographical base (permitting medical record and school linkage; environmental measures in the home, and clinics for direct examination); annual hands-on examinations of the full cohort since age 7. The 14541 enrolled pregnancies (expected date of delivery 1 April 1991 to 31 December 1992) represented about 85\% of the eligible population. The 13971 children who were still alive at age 12 months have been followed principally by questionnaires completed by a parent. Twelve years on, questionnaires are still being sent out to 11300 families. The average questionnaire response rate from mothers is $79 \%$. From age 7 , annual examinations of both 'physical' and 'psychological' aspects have also been conducted on the children (approximately 8000 attend each 'clinic'). The quality of the data has proved high in validation studies and is maintained by collaboration with experts in each specialist field. The high participation rate ensures a viable study well into the future.
\end{abstract}

European Journal of Endocrinology 151 U119-U123

\section{The study aims}

The Avon Longitudinal Study of Parents and Children (ALSPAC), also known as Children of the Nineties, was the result of 5 years of planning and piloting. The overall objectives of the study are to understand the ways in which the physical and social environments interact over time with genetic inheritance to affect health, behaviour and development in infancy, childhood and then into adulthood (1).

A diagrammatic structure of the way in which we have designed the study is shown in Fig. 1. Here it can be seen that the environmental influences that we are considering include psychosocial conditions, features of parenting strategies, the diet and lifestyle of the family, the pollutants (including those in the air, water and food), housing circumstances, health behaviour of the family, medical and dental care (including medications taken), the types of day care and the schooling that the child receives. It is anticipated that the outcomes will depend on complex interactions between the environment and variation in a number of different genetic polymorphisms. Consequences that are being measured in this study include growth, onset of obesity, respiratory function, traits relevant to adult-onset diseases, infections, motor and mental ability, educational achievements, sexual development, accidents and injuries, atopic diseases including asthma, eczema and specific allergies, mood behaviour and temperament. From late adolescence onwards ALSPAC will be able to study the genesis of type 2 diabetes, markers of increased susceptibility to coronary heart disease, schizophrenia and other psychotic disorders, criminal behaviour, ability to hold down a job, onset of drug and alcohol abuse and reproductive successes and failures.

\section{The study area}

Avon itself is situated in England - it is an area bordering the Severn estuary and is about 120 miles due west of London (Fig. 2). The study area (total population 1 million) includes a major city of population 0.5 million 


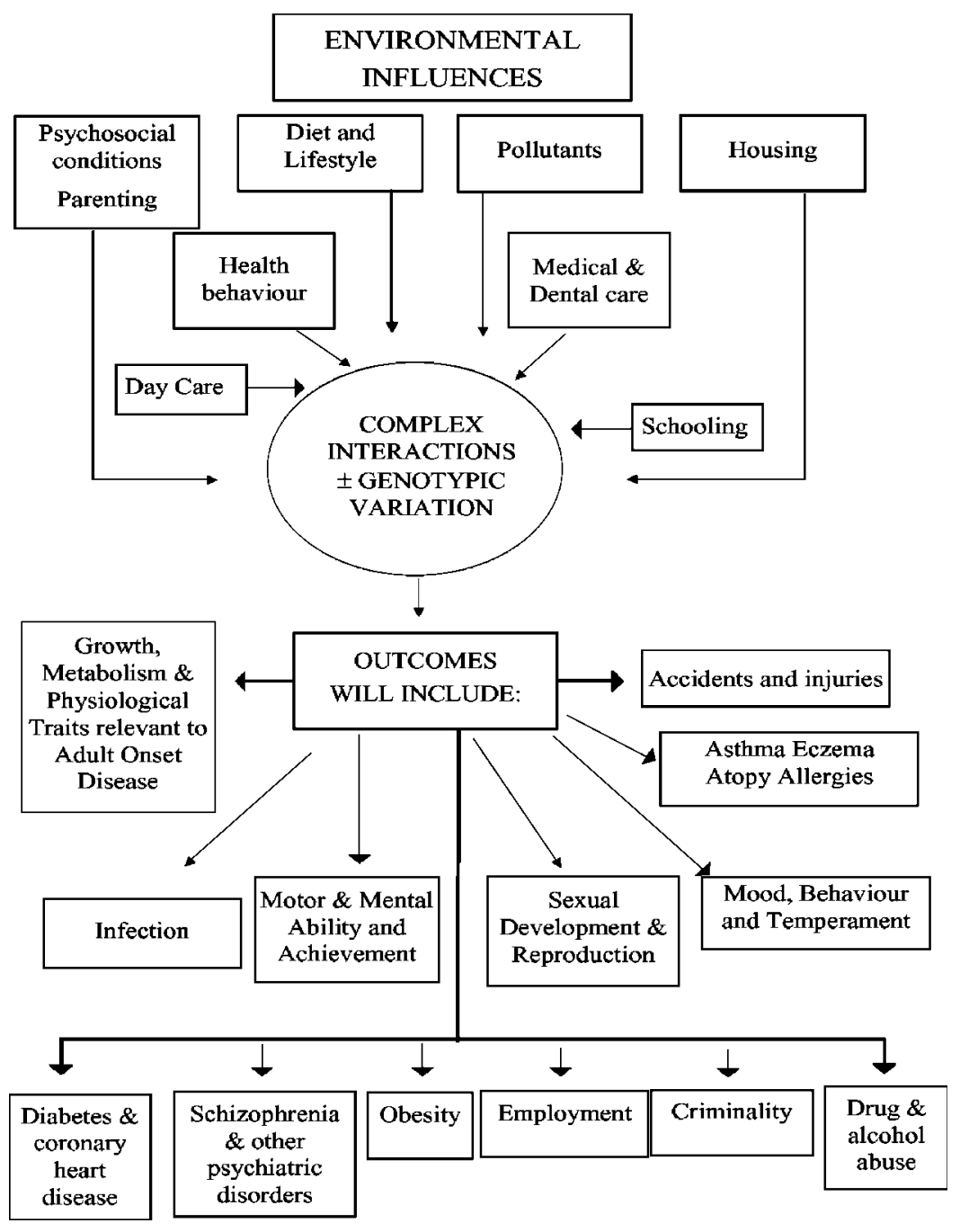

Figure 1 Diagrammatic plan of the aims of the study.

(Bristol) and surrounding areas, which include small towns, villages and farming communities. Avon has the advantage of being a defined geographic area with services centralised around Bristol. It has a relatively low level of outward migration and a mixture of different social backgrounds, housing types and urban and rural areas.

\section{Study enrolment}

The study itself started as early in pregnancy as possible. Eligible women were those who were pregnant, resident in the study area and had an expected date of delivery between 1 April 1991 and 31 December 1992.

Of all mothers who were interested in taking part, an estimated $85 \%$ of the eligible population were included and answered at least one questionnaire. This resulted in 13971 babies born who were alive at 12 months and have been eligible for follow-up ever since.

\section{Data collection}

The ALSPAC data are collected using a variety of different mechanisms, including those in the following subsections.

\section{Self-completion questionnaires}

Detailed questionnaires have been and are answered by mothers, their partners and from the age of 5 onwards, their children, as well as the child's school teacher.

A sample of the response rates to the questionnaires sent to mothers relating to the child is shown in Table 1. This indicates the increasing numbers who either refused or whose address was lost over time, 


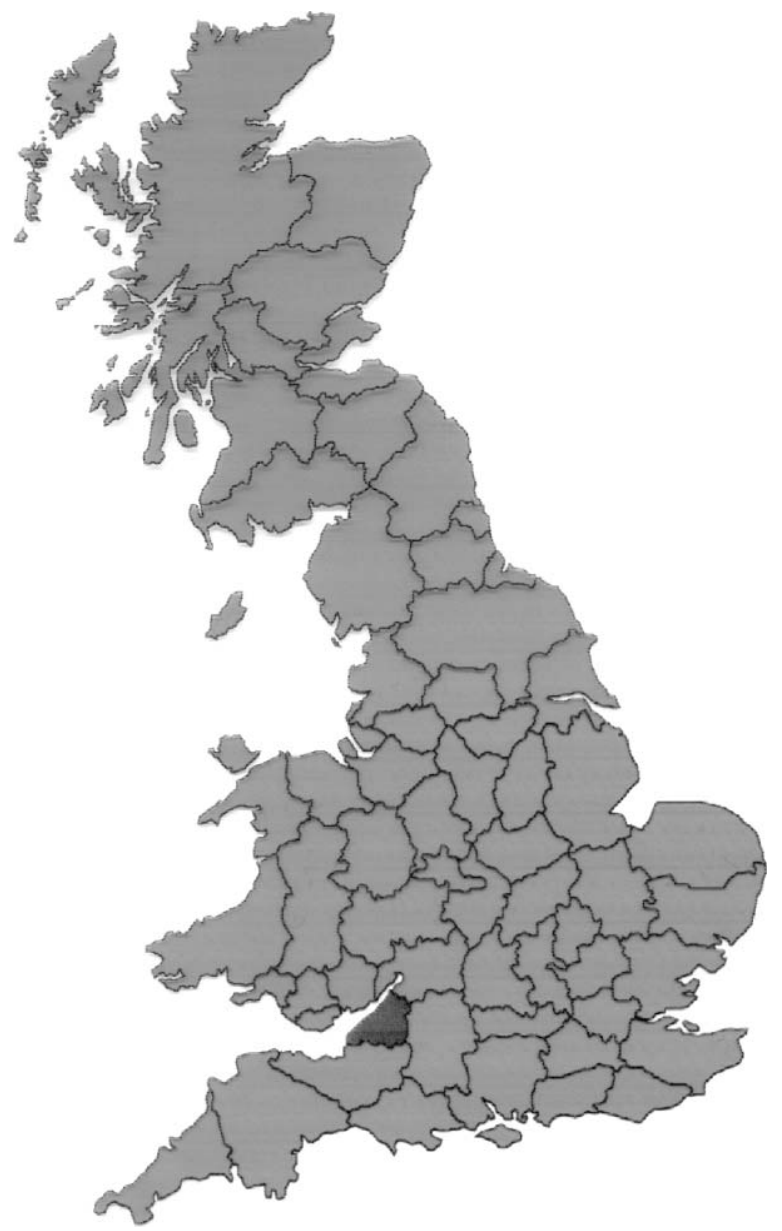

Figure 2 Location of Avon within the UK.

but the relatively high response rate from those parents to whom the questionnaires were sent $(80-90 \%)$.

\section{Health records}

These involve the detailed abstraction of obstetric records, linkage to the immunisation and childgrowth database, and specific studies carried out on an ad hoc basis.

Table 1 Child-based questionnaires.

\begin{tabular}{lcccc}
\hline $\begin{array}{l}\text { Age } \\
\text { (months) }\end{array}$ & Eligible & $\begin{array}{c}\text { Refused and } \\
\text { other }^{\mathrm{a}}(\%)\end{array}$ & Sent & $\begin{array}{c}\text { Response } \\
(\%)\end{array}$ \\
\hline 1 & 14010 & 2.5 & 13659 & 90.4 \\
6 & 13994 & 3.6 & 13491 & 85.2 \\
15 & 13983 & 5.5 & 13217 & 83.8 \\
18 & 13982 & 6.7 & 13040 & 85.3 \\
24 & 13980 & 8.3 & 12826 & 81.3 \\
30 & 13977 & 9.3 & 12683 & 81.4 \\
38 & 13977 & 10.5 & 12510 & 79.7 \\
42 & 13974 & 11.0 & 12434 & 80.9 \\
\hline
\end{tabular}

a Includes lost to follow-up and mothers who requested no questionnaires for the moment.

\section{Biological samples}

Maternal samples of blood and urine were collected at various times during the prenatal period; cord blood and a piece of the umbilical cord, were obtained at birth and the whole placenta was fixed in formalin; hair and toe nail samples were requested from the study child and parents, as were the child's milk teeth. From the age of 7 onwards, samples of the study children's blood, urine and saliva were taken at various time points.

No biological samples are assayed without the signed permission of the mother. DNA has been extracted from both maternal blood and the child's blood (preferentially using samples collected at 7 years or later, but failing this from the cord blood). In all, over 10000 samples from mothers and 10300 child samples are available for DNA assays.

\section{Environmental monitoring}

Subsamples of the study have had specific measurements taken in the home, concerning air pollutants and electromagnetic radiation (these results have been compared with questionnaire-based measures to allow imputed estimate of pollutants for each home). In addition, geographic information systems (GIS) mapping allows assessment of outdoor air pollutants and questionnaires provide further information on physical and psychosocial environmental features of the home and lifestyle.

\section{Education records}

Access to the study child's education test results is based on statutory testing of all children in schools in the public sector (95\% of all children are included). In addition teachers have supervised ALSPAC-specific maths and science awareness tests.

\section{Observations in the home}

A large number of different projects related to different aspects of the home and the children. These include, for example, studies of inter-relationships within stepfamilies (2), children being brought up in lesbian homes (3), the development of speech and language in twins (4), the relationship between alcohol consumption of the breastfeeding mother and motor development of the child (5) and the relationship between maternal anxiety in pregnancy and child behaviour (6).

\section{Testing and interviewing the study children in ALSPAC clinics}

This occurred for a 10\% sample of the children randomly selected from the last 6 months of study births; these children were seen by the study team at 4,8 and 12 months and then at 6-monthly intervals 
thereafter until age 5. Data collected included anthropometry, tests of vision and hearing, categorisation of otitis media with effusion, blood pressure, physical fitness, motor and intellectual developmental tests, speech and language tests and a variety of other aspects of development.

From the age of 7 all children in the study have been invited to visit for a half day of tests annually. Detailed measurements include anthropometry; blood pressure; physical fitness; dual-energy X-ray absorptiometry scans, which identify bone mineralisation and amount of fat and lean tissue; lung function and bronchial hyper-responsiveness; reading, spelling and phoneme awareness; standardised interviews to assess: gender role behaviour, bullying and victimisation, antisocial (delinquent) behaviour, sexual experimentation, use of drugs of addiction including alcohol and cigarettes, as well as cannabis and hard drugs, levels of depression, borderline personality disorder and self esteem; cognitive tests including IQ, executive function, non-verbal recognition and attention span; detailed measures of vision and hearing, motor coordination and balance.

\section{Advantages of one geographic region}

The study is not a national study - it is based in one geographic region and in consequence has a number of advantages. By being in one area we have been able to efficiently reinforce the commitment of the involved families through the local media; we have been able to access medical records easily (there is just one children's hospital in the area), and the link with schools is very efficient. In addition, the way in which biological samples have been able to be collected during pregnancy and delivery was made much easier by being local and fitting into the normal schedule by which biological samples were forwarded to local laboratories for clinical assays.

\section{Advantages of a longitudinal study}

The value of longitudinal studies compared with crosssectional focused studies relates to: (i) a reduction in retrospective bias from the participants, (ii) the ability to take biological samples and environmental measures at appropriate time points, (iii) the temporal resolution of associations into antecedents, and (iv) the monitoring of changes in phenotype with age.

\section{Conclusion}

The ALSPAC study has shown itself to be highly successful (with relatively high response rates) with the continuing support of the participants, a wealth of information collected to date, and a large number of collaborating scientists who are world leaders in a variety of fields. There is now interest in a number of countries in doing a similar study, most notable being the National Children's Study in America, which is planned to enrol 100000 pregnancies. ALSPAC is at least 15 years ahead of any new large study and could be considered as a pilot resource for planning for future studies.

The study itself is set up as a resource for scientists in a variety of disciplines. The Director of the study has always been open to approach from other scientists to discuss ways in which collaborations could be progressed. The Director answers to a number of advisory subcommittees and each new proposal has to be assessed by one or more of these as well as by the ALSPAC Ethics and Law Committee where relevant.

Funding for the study has been achieved by piecing together specific project grants focused on the study together with some core funding from the Wellcome Trust and the Medical Research Council. The study has benefited hugely from support from the University of Bristol. However, the study could not possibly continue without the full support of the study participants. These have shown themselves to be particularly committed, even though they have been told from the start that the study is unlikely to provide them with any tangible benefit - but rather that it does have the potential to protect the next generation from a variety of adverse effects. The ALSPAC website (www.alspac.bris.ac.uk) provides up to date findings from the study, and abstracts of each publication. The website includes details of the data collected at different time points including the full text of all questionnaires.

Of interest to the endocrinology community are results concerning the link between birthweight and postnatal growth on (i) insulin sensitivity and secretion in childhood (7), (ii) adrenarche (8), (iii) plasma insulin-like growth factor levels (9), and (iv) the relationships with the insulin gene (10). The study has shown also that the young girl who prefers more boyish types of play was exposed to higher levels of maternal testosterone in utero (11), and that hypospadias is found more frequently in boys whose mothers eat a vegetarian diet (12). Ongoing studies are related to factors associated with early signs of the onset of puberty, as well as the development of obesity.

\section{Acknowledgements}

We are extremely grateful to all the mothers who took part and to the midwives for their cooperation and help in recruitment. The whole ALSPAC Study Team comprises interviewers, computer technicians, laboratory technicians, clerical workers, research scientists, volunteers and managers who continue to make the study possible. This study could not have been undertaken 
without the financial support of the Medical Research Council, the Wellcome Trust, UK government departments, medical charities and others. The ALSPAC study is part of the WHO initiated European Longitudinal Study of Pregnancy and Childhood.

\section{References}

1 Golding J, Pembrey M Jones R \& ALSPAC Study Team, ALSPAC The Avon Longitudinal Study of Parents and Children. I. Study methodology. Paediatric and Perinatal Epidemiology $2001 \mathbf{1 5}$ $74-87$.

2 Dunn J, Davies LC, O’Connor TG \& Sturgess W. Family lives and friendships: the perspectives of children in step-, single-parent, and nonstep families. Journal of Family Psychology $2001 \mathbf{1 5}$ 272-287.

3 Golombok S, Perry B, Burston A, Murray C, Mooney-Somers J, Stevens M \& Golding J. Children with lesbian parents: a community study. Developmental Psychology $20033920-33$.

4 Thorpe K, Rutter M \& Greenwood R. Twins as a natural experiment to study the causes of mild language delay: II: Family interaction risk factors. Journal of Child Psychology and Psychiatry $200344342-355$.

5 Little RE, Northstone K, Golding J \& ALSPAC Study Team, Alcohol, breast feeding and development at 18 months. Pediatrics 2002109 e72. (http://www.pediatrics.org/cgi/content/full/109/ 5/e72).

6 O'Connor TG, Heron J, Golding J, Glover V \& ALSPAC Study Team. Maternal antenatal anxiety and behavioural/emotional problems in children: a test of a programming hypothesis. Journal of Child Psychology and Psychiatry 200344 1025-1036.

7 Ong KK, Petry CJ, Emmett PM, Sandhu MS, Kiess WI, Hales CN, Ness A, Dunger DB \& ALSPAC Study Team. Insulin sensitivity and secretion in normal children related to size at birth, postnatal growth and plasma insulin-like growth factor-I levels. Diabetologia 200447 1064-1070.

8 Ong KK, Potau N, Petry CJ, Jones R, Ness AR, Honour JW, de Zegher F, Ibáñez L, Dunger DB \& ALSPAC Study Team. Opposing influences of prenatal and postnatal weight gain on adrenarche in normal boys and girls. Journal of Clinical Endocrinology and Metabolism $2004892647-2651$.

9 Ong K, Kratzsch N, Kiess W, Dunger D \& ALSPAC Study Team. Circulating IGF-I levels in childhood are related to both current body composition and early postnatal growth rate. Journal of Clinical Endocrinology and Metabolism 200287 1041-1044.

10 Ong KKL, Phillips DI, Fall C, Poulton J, Bennett ST, Golding J, Todd JA \& Dunger DB. The insulin gene VNTR, type 2 diabetes and birth weight. Nature Genetics 199921 262-263.

11 Hines M, Golombok S, Rust J, Johnston KJ, Golding J \& The Avon Longitudinal Study of Parents and Children Study Team. Testosterone during pregnancy and gender role behavior of preschool children: a longitudinal population study. Child Development 200273 1678-1687.

12 North K, Golding J \& ALSPAC Study Team. A maternal vegetarian diet in pregnancy is associated with hypospadias. British Journal of Urology $2000 \mathbf{8 5} 107-113$.

Received 2 July 2004

Accepted 8 September 2004 